\title{
Interest Rate Determination in China: Past, Present, and Future*
}

\author{
Dong He, ${ }^{\mathrm{a}}$ Honglin Wang, ${ }^{\mathrm{b}}$ and Xiangrong $\mathrm{Yu}^{\mathrm{b}}$ \\ anternational Monetary Fund \\ ${ }^{\mathrm{b}}$ Hong Kong Monetary Authority
}

\begin{abstract}
How should we think about the determination of interest rates in China after interest rate liberalization? Would effective deposit rates, lending rates, and bond yields move higher or lower? We argue that interest rates in a liberalized environment would need to be anchored by monetary policy. To achieve price and output (or employment) stabilization, the policy rate should be set close to China's equilibrium or natural rate. We sketch three preliminary approaches to estimation of the natural rate. Based on this analysis, we argue that interest rates on large deposits and short-term money-market rates would likely move higher following liberalization. The effect on effective lending rates is somewhat ambiguous, as the contestability of the banking sector and the competition from the bond markets are likely to increase. We leave the determination of the curvature of the yield curve to future research.
\end{abstract}

JEL Codes: E43, E52, O53, P24.

\section{Introduction}

Interest rate liberalization is an essential part of China's price reforms. While most goods and services are now market determined,

*The authors would like to thank Steve Barnett, Yi Gang, John C. Williams, and one anonymous referee, as well as participants at the conferences held at the China Finance 40 Forum in September 2013 and at the Hong Kong Institute for Monetary Research in January 2014 for their comments on the paper. The views expressed in this paper are those of the authors and do not necessarily reflect those of their affiliations. Author contact: dhe@imf.org (He), wanghonglinmail@yahoo.com (Wang), and xiangrongyu@gmail.com (Yu). 
there remain significant government controls on prices of the factors of production. Ceilings imposed by the People's Bank of China (PBC) on deposit rates are a notable binding constraint on price discovery in the financial markets. Even though interest rates in the money and bond markets and bank lending rates are now market determined, their levels and movements are constrained by regulated deposit rates, due to the dominance of the banking sector in overall financial intermediation. The Chinese authorities have recently announced plans to speed up the pace of interest rate liberalization, raising the expectations of a final removal of the deposit rate ceilings in the medium term. Accompanying the process will be an overhaul of the monetary policy framework, away from a focus on credit targets toward a focus on interest rates, and an expansion of the fixed-income markets, facilitating the formation of a complete risk-free yield curve.

How should we think about the determination of interest rates in China after they are fully liberalized? Would effective deposit rates, lending rates, and bond yields move higher or lower? In this paper we argue that interest rates in a liberalized environment would need to be anchored by monetary policy. To achieve price and output (or employment) stabilization, the policy rate should be set close to China's equilibrium or natural rate. We sketch three preliminary approaches to estimation of the natural rate. Based on this analysis, we argue that interest rates on large deposits and money-market rates would likely move higher following liberalization. The effect on effective lending rates is ambiguous, as the contestability of the banking sector and the competition from the bond markets are likely to increase.

At present, the ceilings on deposit rates are imposed by the PBC through administrative orders. After interest rate liberalization, the $\mathrm{PBC}$ will use the composition and size of its own balance sheet to influence market rates. As the monopoly supplier of high-powered money, the $\mathrm{PBC}$ will be in a good position to steer short-term interest rates. As an interim measure, the PBC may still need to set targets for medium-term rates and manage the shape of the yield curve through direct interventions. This is because the bond markets will take time to expand and mature. 


\section{Current Interest Rate Structure}

In the past three decades, China has made substantial progress toward a market-oriented system of interest rates. According to Yi's (2009) account, more than 123 interest rates had been liberalized and only 24 interest rates were still regulated as of the end of 2008 . At present, interest rates can be grouped into the following four types.

\subsection{Interest Rates for Central Bank Operations}

In the era of the planned economy, financial resources were allocated by government plans, and all interest rates were set by the central bank. The PBC, as the only bank in the economy, used a system of "centralized deposits and credits" to manage funds. Financial reforms in the early 1980s helped to establish a commercial banking system dominated by a number of large state-owned banks. The PBC began to function exclusively as a central bank in 1984, and a series of interest rates were created to conduct monetary and financial stability policy along with other quantitative instruments such as loan quotas and reserve requirements.

Interest rates for $\mathrm{PBC}$ operations can be divided into three types: first, lending rates of refinance facilities, including central bank relending rates, rediscount rates, and lending rates of the recently created Standing Lending Facility (SLF); second, deposit rates for required reserves and excess reserves; third, open-market operation (OMO) rates, including central bank repo rates, central bank bill rates, and interest rates of the newly created short-term liquidity operations (SLO). Figure 1 shows changes in rediscount rates and reserve interest rates in the last decade. In recent years, the central bank repo rates and central bank bill rates have become increasingly important tools to signal the PBC's policy intentions and to guide market interest rates toward desired levels (Zhang 2012).

\subsection{Interest Rates of Banking Products}

In the banking sector, most deposit rates are regulated through administratively imposed ceilings, and there were lending rate floors before they were removed in July 2013. As shown in figure 2, the 
Figure 1. Interest Rates for Central Bank Operations

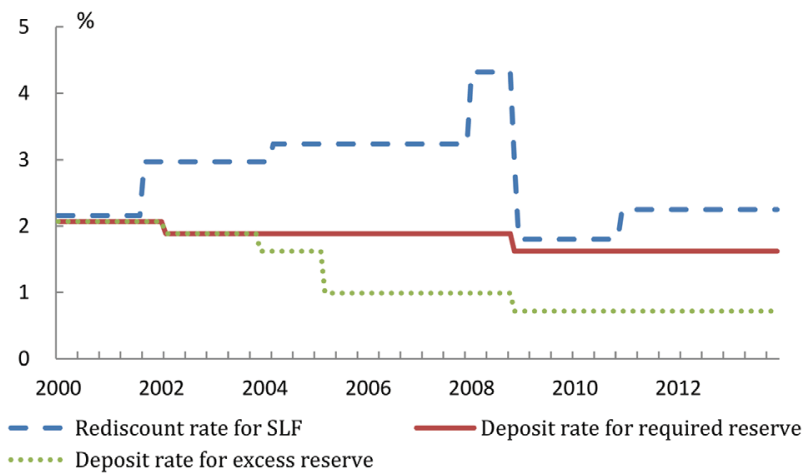

Source: CEIC.

\section{Figure 2. Deposit Rates of Different Tenors}

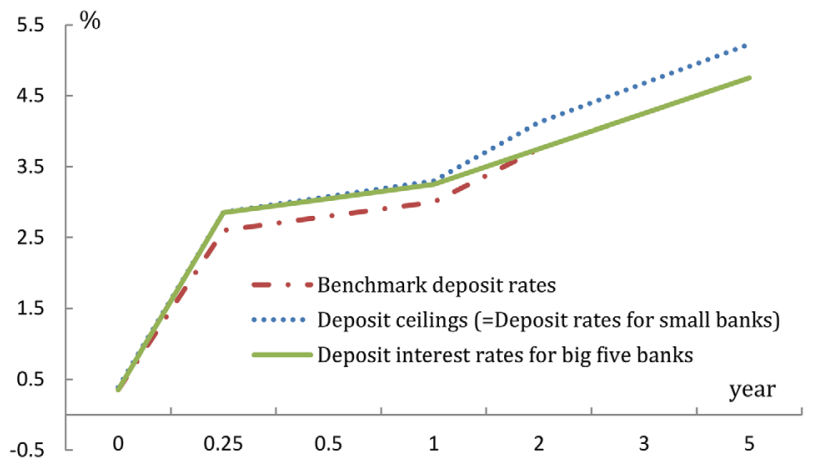

Source: CEIC.

PBC implicitly shapes the term structure by imposing ceilings on deposit rates of different maturities. These ceilings are the most powerful instrument to affect market interest rates and bank lending rates, and they help to anchor the whole interest rates system (He and Wang 2012, 2013). This is because deposits are the main funding source for commercial banks, which dominate the Chinese financial system. On the other hand, although no longer regulated, lending rates may not fully reflect market forces: First, aggregate 
loan supply is in practice subject to an implicit credit target 1 Second, lending rates are affected by regulated deposit rates owing to market frictions such as "tie-up" contracts that require borrowers to deposit their cash in the lending bank in order to obtain the credit.

Interest rates used internally by banks for capital budgeting and transfer pricing are still based on benchmark deposit rates instead of market rates such as repo rates (Jiang 2012). This further illustrates the anchor role of regulated deposit rates in the banking sector.

\subsection{Interest Rates in the Money and Bond Markets}

The interbank lending market in China was established in the mid1980s. A unified trading platform was established in Shanghai in 1996 to enhance the surveillance on interbank activities, based on which the China Interbank Offered Rates (CHIBORs) formed. With more stringent regulations on uncollateralized interbank lending, the introduction of the repo market in 1997 soon replaced the interbank loan market to become the major source of short-term liquidity for banks. The rapid growth of the repo market increased the need for reference rates to price money-market instruments, resulting in the compilation of repo fixing rates for overnight, seven-day, and fourteen-day tenors. The high turnover made the corresponding fixing rates a widely used benchmark in the interbank market. However, the relatively short maturity in repo transactions has restrained interbank funding with longer tenors. The authorities also realized that a benchmark money-market yield curve would enhance the efficiency of price discovery. As a result, the Shanghai Interbank Offered Rates (SHIBORs) were introduced in January 2007, which not only increased turnover in the interbank loan market but also facilitated the pricing of a range of interest rate derivatives.

Due to the more stringent regulations on interbank lending at longer maturities, a large portion of interbank transactions are concentrated at short tenors of one month or less. Over 90 percent of transactions in the interbank market were overnight or at seven-day tenors in 2013, and more than half of the trading days registered

\footnotetext{
${ }^{1}$ In practice, the $\mathrm{PBC}$ still uses moral suasion, so-called appropriate loan amount (implicit loan quota), to influence lending activities of commercial banks. For example, when this quota becomes binding for a bank at the end of the quarter, borrowers might have to pay higher interest rates to compete for loans.
} 
no transactions for lending of six months to one year in the repo and interbank loan markets during the period 2010 to 2013. This uneven distribution has restrained use of the money-market rates as the benchmark for pricing loans with longer maturities such as corporate and syndicated loans.

The Chinese bond markets also took off in the middle of the 1980s, and the interbank bond market has grown very rapidly since the mid-2000s. However, the bond markets remain segmented between the interbank market and the exchange market, and liquidity is relatively low compared with those in advanced economies. Anecdotal evidence suggests that entry to the primary market is still somewhat restricted. Prices in the secondary market are largely market determined. However, some regulations on the pricing of bonds remain, though they may not be fully enforced. For example, the issuing rates of corporate bonds cannot be 40 percent higher than benchmark deposit rates with the same maturity. In addition, the maximum issuing size is only up to 40 percent of the issuers' net assets.

It is worth noting that observed interest rates in the money and bond markets not only reflect market forces but are also influenced by regulated bank rates. As shown in figures 3 and 4 , both the seven-day repo rate and the one-year treasury yield seem to follow the pattern of the regulated one-year deposit rate.

\subsection{Interest Rates in Other Financial Markets}

One important recent development in the Chinese financial system is the increase in off-balance-sheet and shadow banking activities, which are incentivized by a desire to circumvent interest rate regulations and demand for alternative investment opportunities. Interest rates in the shadow banking sector are largely market determined but constrained by deposit rate regulations. Although more volatile, interest rates on wealth-management products are closely linked to interest rates on formal deposits (figure 5).

In contrast to shadow banking rates, interest rates in the informal credit markets seem much more opaque and higher (figure 6). Higher interest rates can be partially attributed to higher risk premia in the informal markets, in which major borrowers are small and medium enterprises. Despite their opacity, informal lending rates do 
Figure 3. Seven-Day Repo Rate and One-Year Deposit Rate

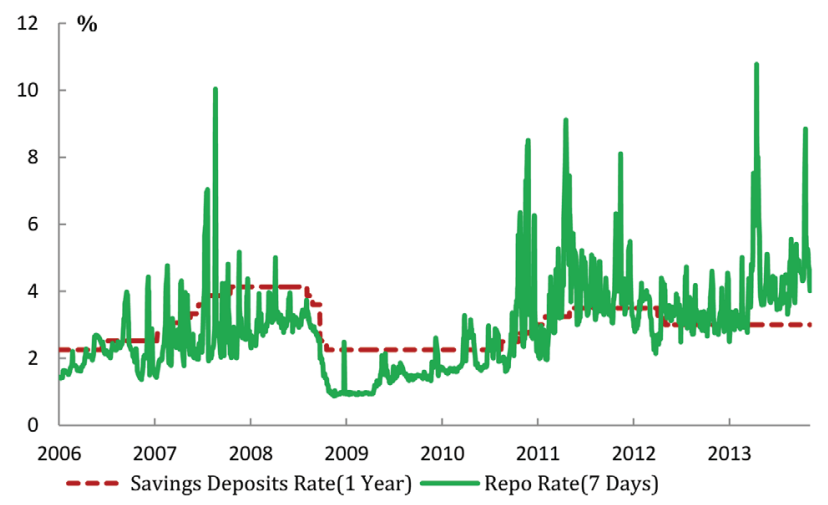

Source: CEIC.

Figure 4. One-Year Treasury Yield and One-Year Deposit Rate

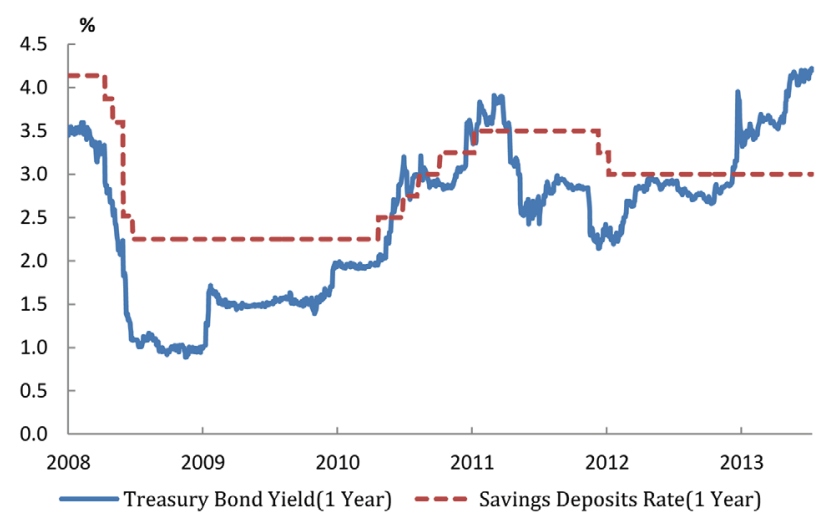

Source: CEIC and WIND.

react to changes of monetary policy and deposit rates (Qin, $\mathrm{Xu}$, and Zhang 2013).

\section{Rationale for Interest Rate Controls}

Why does China still retain control of deposit rates in the banking sector? There are a number of explanations. According to Lardy 
Figure 5. Interest Rates on Wealth-Management Product and Three-Month Deposit

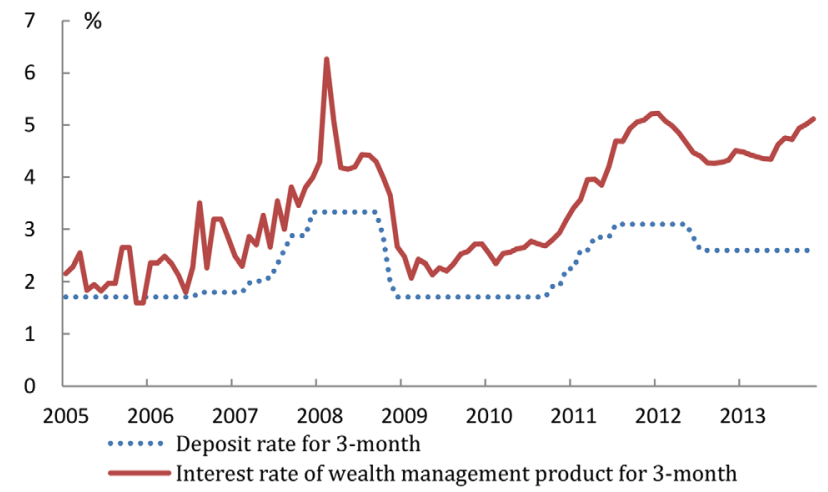

Source: CEIC and WIND.

Figure 6. Lending Rates in the Informal Credit Market and Bank Lending Rate

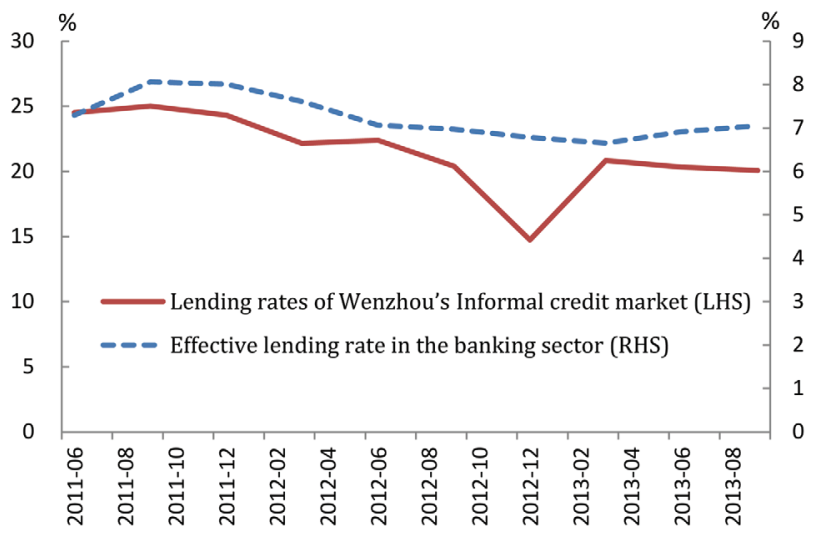

Source: CEIC and WIND.

(2008), bank rates are kept at artificially low levels to extract transfers or subsidies from households to the corporate sector, particularly the state-owned enterprises (SOEs), and this is part and parcel of a state-led development strategy. In contrast, PBC officials tend to emphasize that interest rate liberalization requires major players 
Figure 7. Credit Market with Interest Rate Distortions

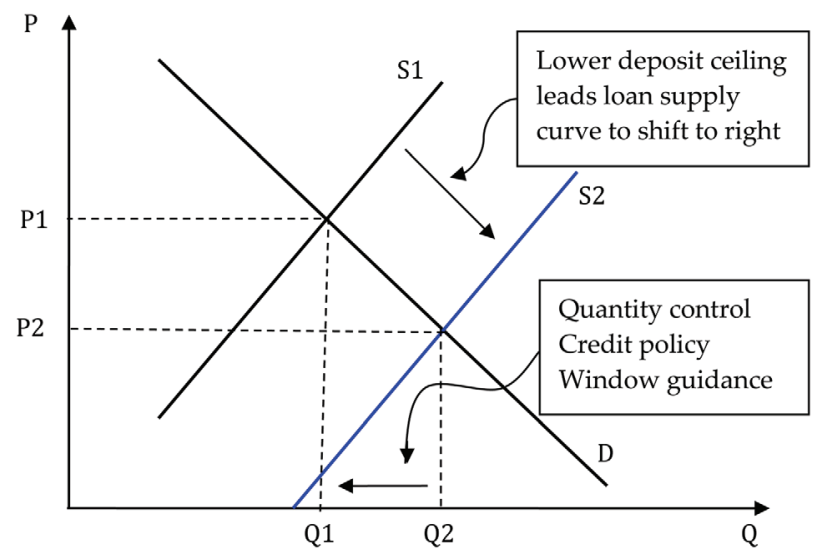

Source: He and Wang (2012).

in the financial system to have hard budget constraints and be in a position to exercise self-discipline in their pricing decisions, and that the demand for credit by borrowers should also be sensitive to interest rates (Zhou 2010). However, banks and their borrowers, particularly SOEs, have not met these standards yet. In addition, when the bond markets are underdeveloped, monetary policy seems more effective through direct interest rate controls rather than through market transmission.

Regardless of policy intentions, in a situation in which the deposit rate ceilings are persistently below their equilibrium level, the PBC must rely on quantity-based instruments to achieve its policy objectives. As shown in figure 7, a lower deposit rate ceiling (compared with its equilibrium level) shifts the loan supply curve of commercial banks to the right $(\mathrm{S} 1 \rightarrow \mathrm{S} 2$, where $\mathrm{S} 1$ is the supply curve without the deposit rate ceiling). With the shifted supply curve (S2), banks are willing to lend at lower interest rates because their funding costs are lower than they should be $(\mathrm{P} 2<\mathrm{P} 1)$. Meanwhile, the demand for loans is also higher than its equilibrium level (Q2 > Q1). However, in the new equilibrium under the deposit rate ceiling (P2, Q2), there is more credit $(\mathrm{Q} 2>\mathrm{Q} 1)$ in the economy compared with the original equilibrium (P1, Q1), which may be inconsistent with the PBC's inflation target. The PBC will then have to constrain credit 
supply using quantity-based instruments such as aggregate credit quotas and reserve requirement ratios. Alternatively, a lending rate floor may be used to curb loan demand through higher borrowing costs, as was the case until recently. A lending rate floor together with a deposit rate ceiling guaranteed profit margins for banks.

This simple analysis demonstrates that distortions caused by price regulations have to be corrected by quantity-based instruments. The importance of quantity-based instruments diminishes when the deposit rate ceilings are close to the equilibrium level of deposit rates. Thus, a necessary step in moving toward a primarily price-based monetary policy framework in the broader context of interest rate liberalization is for the $\mathrm{PBC}$ to move and maintain its benchmark or policy interest rates close to their equilibrium levels.

\section{Interest Rate Determination after Full Liberalization}

In a typical modern market economy, short-term rates are largely anchored by the central bank's policy rate, while longer-term rates are mainly determined by market forces, adjusting for term and risk premia. We believe that the PBC's framework would eventually converge to one like this. Although this process may take time, a useful first step is to understand the factors that would shape the PBC's analytical thinking in determining its own policy rate.

Operationally, a fundamental change is that the PBC will use the composition and size of its own balance sheet to control and influence market rates instead of using administrative others to regulate rates. As an interim measure, the $\mathrm{PBC}$ may consider setting targets for both short- and medium-term interest rates and managing the shape of the yield curve through direct interventions in the bond markets. This is because the bond markets will take time to expand and mature to develop an effective yield curve determined primarily by market forces. With this big picture in the mind, we discuss the formation of policy rates, bank rates, and market rates in the post-liberalization era in the rest of this section.

\subsection{The Determination of Policy Interest Rates}

The PBC has not yet articulated in public the contours of its monetary policy framework after interest rate liberalization. In our view, 
it would likely involve setting targets for short-term interest rates through OMOs in the money markets. The Taylor rule is then a simple analytical tool for understanding the conduct of monetary policy, which specifies adjustment of the policy rate around the natural rate of interest.

The notion of the "natural," "equilibrium," or "neutral" rate of interest, which are sometimes used interchangeably, has been developed in the literature to provide a benchmark summarizing the economic circumstances against which we evaluate interest rates. It can be defined as the equilibrium real interest rate consistent with stable low inflation and potential output, in the absence of transitory shocks to demand and supply 2 We use different methods to gauge the natural interest rate in China. The purpose is not to establish a precise number but to provide a robust starting point for future policy experiments.

\subsubsection{Calibration-Based Estimates}

The seminal work by Laubach and Williams (2003) estimated the natural real interest rate and potential output growth jointly by applying Kalman filtering techniques to a system of reduced-form equations that describe relations between the natural rate and observables such as output and inflation. Garnier and Wilhelmsen (2005), Manrique and Marqués (2004), and Mesonnier and Renne (2007), among others, followed a similar methodology to measure the natural rate of interest for different economies.

This method cannot be applied directly to the Chinese data. Without a structural model characterizing the influence of interest rate controls on observables, the specification applicable to advanced economies with free interest rates cannot correct for the potential institutional bias in China. Nevertheless, the critical equation in Laubach and Williams (2003) is

$$
r^{*}=\frac{1}{\sigma} g+\theta
$$

\footnotetext{
${ }^{2}$ Estimation of the natural rate should correct for the effect of interest rate controls and financial constraints in China. We are interested in the natural rate after liberalization, while the actual data on interest rates and other macroeconomic variables that we observe contain systematic distortions.
} 


\section{Table 1. Natural Interest Rates under Different Calibrations}

\begin{tabular}{|l|c|c|c|c|}
\hline Parameter & (1) & (2) & (3) & \multicolumn{1}{|c|}{$(\mathbf{4})$} \\
\hline Intertemporal Elasticity of & 2.20 & 2.00 & 2.00 & 1.53 \\
$\quad$ Substitution $(\sigma)$ & & & & \\
Time Preference $(\theta)$ & $0.3 \%$ & $0.3 \%$ & $0.45 \%$ & $0.45 \%$ \\
Potential Economic Growth $(g)$ & $7.5 \%$ & $7.5 \%$ & $7.5 \%$ & $7.5 \%$ \\
Natural Interest Rate & $3.71 \%$ & $4.05 \%$ & $4.2 \%$ & $5.35 \%$ \\
\hline Source: Authors' calculation.
\end{tabular}

where $r^{*}$ is the natural real interest rate, $\sigma$ is the intertemporal elasticity of substitution (IES), $g$ is the growth rate of potential output, and $\theta$ is the rate of time preference. This simple relation holds in the steady state for a wide range of models. It can be derived from neoclassical models like Ramsey (1928) 3 In New Keynesian models, the natural rate can be written in a similar form (Gali 2003). We may use equation (1) to infer the natural rate of interest by calibrating the parameters.

We choose parameter values that we consider reasonable for China. Following Song, Storesletten, and Zilibotti (2011), we calibrate $\theta$ to 0.3 percent to match China's average aggregate saving rate. Given the high saving rate, research generally assumes that households in China are more "patient" than in other economies. For example, the calibration of Funke and Paetz (2013) corresponds to an average $\theta$ of 0.45 percent. For the IES, we use the value set by Song, Storesletten, and Zilibotti (2011) as a baseline, i.e., $\sigma=2$. Garnier and Wilhelmsen (2005) estimated $\sigma$ to be around 1.53 for Germany. As a similar high saving economy, we use this value as another reference. To reflect potentially higher intertemporal substitution, we also consider 2.2 for $\sigma$. For potential growth, we set $g$ at 7.5 percent in light of the historical experience and the recent economic slowdown.

We obtain estimates for the natural interest rate in China in table 1 . Columns 2 and 3 seem to be reasonable baseline estimates,

\footnotetext{
${ }^{3}$ We derive equation (1) in the context of the Ramsey model in the appendix.
} 
while columns 1 and 4 can be considered the lower and upper bounds under our parameterization. Based on these results, the natural rate in China is about 4 percent or slightly higher.

Of course, these estimates depend on our choice of parameter values. For example, if economic growth slows to 7 percent, the natural rate will adjust downward by 0.25 percent in the baseline case 4 The reasonable range for the IES is also wide, and we hope that future research can provide evidence for the IES in China.

\subsubsection{Marginal Returns to Capital}

Our second approach is to measure the natural interest rate using equilibrium conditions from the production side of the economy. We consider a standard macroeconomic model featuring a constantreturns-to-scale production function. Under the assumption of competitive markets, total output is distributed among factors according to their marginal productivity, without surplus or deficit. With these minimal conditions, the marginal product of capital $M P K$ is given by

$$
M P K=\frac{\alpha}{K / Y}
$$

where $Y$ is the total output, $K$ is capital stock, and $\alpha$ is the share of capital income. The equilibrium interest rate $r^{*}$ then equals the marginal product of capital net of tax and depreciation:

$$
r^{*}=(1-\tau)(M P K-\delta),
$$

where $\tau$ is the ratio of tax on capital income and $\delta$ is the depreciation rate. All variables are expressed in real terms. The tax deduction of depreciation expenses is allowed.

The output $Y$ is proxied by China's GDP from the National Bureau of Statistics (NBS) deflated by the GDP deflator provided by the International Monetary Fund (IMF). We use the perpetual inventory method to construct estimates of the capital stock. To be

\footnotetext{
${ }^{4}$ Some observers are concerned about the possibility of more dramatic slowdown, but the natural interest rate is a concept more relevant in normal situations.
} 
consistent with the measure of the World Bank (2011), on which our method will partly rely, we proxy investment by gross capital formation deflated by the fixed-asset investment price index. 5 The initial capital stock is given by the ratio of the first-year investment to the sum of the average growth rate of investment in the first five years and the depreciation rate, which is set at 5 percent. The rest of the capital stock series derives from the capital accumulation process, i.e., adding investment to existing stock, net of depreciation, yields current capital stock. From a macroeconomic viewpoint, capital income includes taxes on both output and enterprise income. We adjust for value-added tax, enterprise income tax, and operation tax, using the NBS data. In general, this construction of the capital stock series is standard, and the results are comparable to those of, for example, Bai, Hsieh, and Qian (2006) and Chow (1993).

In the literature, it is common to back out the capital income share $\alpha$ as one minus the labor share $\alpha_{L}$. However, $1-\alpha_{L}$ includes payments accruing to both produced and natural capital, i.e., land and natural resources. In contrast, the measure of capital stock is calculated from investment flows that cover only machinery, equipment, and plant and therefore only represents produced capital. Using $1-\alpha_{L}$ as the capital share biases the estimate of $M P K$ upwards. Given that agricultural and natural resources have a large share in inputs in developing China, the potential biases can be serious.

To construct $\alpha$, we first calculate the labor share $\alpha_{L}$ by taking the average of the provincial labor shares weighted by GDP using data from the NBS. We then adjust for the payments to natural capital $N$ to obtain the capital income share $\alpha$ corresponding to our measure of produced capital $K$ :

$$
\alpha=\frac{K}{K+N}\left(1-\alpha_{L}\right) .
$$

This method was proposed by Caselli and Feyrer (2007), who documented that the returns to capital are remarkably similar across

\footnotetext{
${ }^{5}$ Here we use different price indices to deflate GDP and investment. In a developing country like China, investment goods are more expensive than final goods. Not accounting for these differential prices can lead to overestimation of the return to capital.
} 


\section{Figure 8. MPK Estimates of the Natural Interest Rate in China}

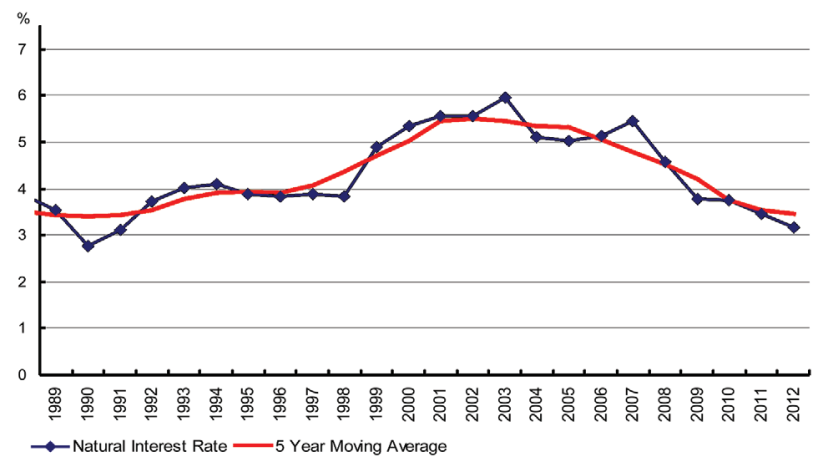

Source: Authors' calculation.

countries after these necessary adjustments. The Wealth of Nations data set compiled by the World Bank (2011) contains estimates of produced and natural capital in 1995, 2000, and 2005. For China, the three observations on the share of produced capital in total capital are $0.45,0.50$, and 0.60 , respectively. We take an average and assume that it prevails across time.

Figure 8 shows that the estimates of the natural real interest rate in China average around 4.3 percent, within a band between 3 percent and 6 percent. The results are relatively stable over time. Since the capital stock partially depends on current investment, which is procyclical, we also provide a moving-average measure to remove high-frequency components. It is worth pointing out that these estimates represent the net returns to capital in an aggregate sense, absorbing the effects of uncertainty and liquidity needs. In this basic non-monetary setting, there is in equilibrium only one interest rate which corresponds to the natural interest rate. Our estimation requires only minimal assumptions of the economic structure, and hence the estimates should be robust to model specification.

\subsubsection{Cross-Country Experience}

Following He and Wang (2012), we correct for the effects of interest rate control and financial repression on market interest rates to 
obtain estimates of the natural rate. They used a panel data set of forty-nine economies between 1973 and 2005 to estimate the linear regression model that links real interest rates $r_{i}$ to real GDP growth rate $g_{i}$, the aggregate saving rate $\theta_{i}$, and the degree of financial repression $\tau_{i}$ :

$$
r_{i}=a_{0}+a_{1} g_{i}+a_{2} \theta_{i}+a_{3} \tau_{i}+\pi_{i}+u_{i},
$$

where $\pi_{i}$ is the country fixed effects. The saving rate is included to capture households' time preference. The real interest rate is the lending interest rate adjusted for inflation as measured by the GDP deflator, which is obtained directly from the World Development Indicators database of the World Bank. The financial repression index is between 0 and 1, compiled by the IMF (2008). It is aggregated from liberalization scores for credit controls and reserve requirements, interest rate controls, entry barriers, state ownership, policies on securities markets, banking regulations, and restrictions on the capital account 6 He and Wang (2012) showed that financial repression has a significant negative effect on observed real interest rates and obtained an estimate of about 4.7 percent for China's natural rate in 2005.

Since data on financial repression are not available after 2005, we cannot update the estimation of (5). Instead, we use linear interpolation to estimate the current level of financial repression in China. Using the empirical results of He and Wang (2012), we remove the distortions caused by financial repression on China's most recent data on real interest rates. A simple moving average is employed to smooth out cyclical shocks. In this way, we find that the natural rate has declined somewhat but remained above the level of 4 percent. The most recent estimate is 4.31 percent for 2012 .

Taken together, our results from the above three methods are largely consistent. A reasonable interval for the estimate of the natural interest rate is between 4 percent and 4.5 percent in China. This is higher than Taylor's (1993) 2 percent and the estimate of Laubach and Williams (2003) of around 3 percent for the U.S. economy. Our methods do not explicitly model the term structure of interest rates.

\footnotetext{
${ }^{6}$ See IMF (2008) for more details. The data set is available at http://www. imf.org/external/pubs/cat/longres.aspx?sk=22485.0.
} 
Corresponding to the policy rate, a small downward adjustment over our estimates may be appropriate.

\subsection{The Determination of Interest Rates in the Banking Sector}

In a fully liberalized interest rate system, it is likely that interest rates on large deposits and negotiable certificates of deposit (CDs) will track wholesale funding costs such as money-market rates closely, whereas interest rates on small deposits would probably be somewhat lower. When market arbitrage works effectively, moneymarket rates and interest rates on large bank deposits and CDs are well anchored by the central bank policy rates. According to our estimates of the natural interest rate, there will be pressures for bank deposit rates to move higher when they are no longer constrained by the binding ceilings, ceteris paribus 7 Indeed, most banks raised their deposit rates close to the ceilings after the PBC announced that the deposit ceilings would be raised from 100 percent to 110 percent of the benchmark deposit rates in 2012 .

The movement of lending rates after liberalization would depend on, among other things, the following three factors. The first is the contestability of the banking industry. Since the effective funding costs of the banking sector (deposits) are set to increase after liberalization, banks might be able to pass higher costs on to their clients if they have sufficient market power, resulting in higher effective lending rates that borrowers have to accept. Second, lending rates will depend on whether the PBC continues to impose an aggregate loan quota and whether the quota is binding after liberalization. If the quota remains binding, the effective loan rate would be determined by the quota and aggregate loan demand. The third factor is the competition from direct finance and foreign inflows after liberalization. If the bond markets are more developed and more firms choose bond markets to finance their projects or foreign lenders are allowed to lend to domestic firms, banks would have to lower their lending rates to compete with the new rivals.

\footnotetext{
${ }^{7}$ As shown in figure 2 , the benchmark rate for the one-year deposit is 3 percent in 2013, up to 110 percent of which banks can offer to depositors. The inflation rate was 2.6 percent in 2013. In this example, the real one-year deposit rate was slightly lower than 1 percent.
} 


\subsection{The Determination of Interest Rates in the Money and Bond Markets}

Interest rates in the money and bond markets after liberalization would be determined by both market forces and monetary policy. As argued earlier, the conduct of monetary policy in the future would mainly involve a policy rate, which is typically a short-term moneymarket rate. As the monopoly supplier of high-powered money, the $\mathrm{PBC}$ in principle can steer the market rate to whatever level desired through its operations in the markets. Given the relatively short yield curve, interest rates in the money markets should be well anchored by monetary policy after liberalization.

In the bond markets, monetary policy would continue to have its influence, in particular, at the short end of the yield curve. According to our estimates of the natural interest rate, short-term bond rates would likely move higher after liberalization. To some extent, the recent rise in China's interbank rates is an indication of such upward adjustment pressures. For longer-term interest rates, market forces would dominate in pricing term and risk premia. The mechanism is complicated, but it is clear that policy signals can still be passed on to the longer parts of the yield curve in deep well-functioning bond markets.

As a final point, market rates and bank rates will affect each other through fund flows between the banking sector and the capital markets. This is consistent with the recent observation that market rates increased as the $\mathrm{PBC}$ lifted the deposit rate ceilings. Shocks from the money and bond markets can also affect bank rates (e.g., lending rates), although the impact is relatively small (He and Wang 2013).

\section{Next Steps}

In a narrow sense, there seems to be only one step left to achieve interest rate liberalization, which is the removal of the deposit rate ceilings. However, its success and the functioning of the financial system in serving the economy afterwards depend on many conditions. It should also be noted that the liberalization process is a dynamic one: market-determined interest rates at the margin will 
help to reduce distorted incentives and moral hazard, thereby creating conditions for further reforms. China's success in other areas of price reform through the dual-track approach bodes well for its success in interest rate reforms.

A carefully designed roadmap is necessary to guide the series of reforms through the process. Governor Zhou (2013) gave his view on how to achieve interest rate liberalization in two steps. In the near term, the focus is to strengthen self-discipline in the formation of market interest rates, to grant financial institutions more discretion in setting their interest rates, to establish the prime lending rate fixing as an effective benchmark for the pricing of loan products, to promote the issuance and trading of negotiable CDs, and to gradually expand the scope of market-based pricing of the liabilities of financial institutions. In the medium term, the focus should be on developing a relatively complete and efficient market interest rate system and improving the monetary policy framework and monetary policy transmission.

The authorities are likely to adopt the following two approaches to deregulation of bank deposit rates. First, the PBC may lift the deposit rate ceilings gradually and allow deposit rates to move upwards in a managed way, and remove the ceiling regulations when actual deposit rates are close enough to their equilibrium levels. Second, the PBC may allow parts of banks' liabilities other than deposits, such as CDs issued by banks, to be priced by market forces. For example, negotiable CDs can be issued to institutional investors first and then extended to individual investors. The face value of a $\mathrm{CD}$ can initially be set large and gradually reduced so that the CDs resemble retail deposits more.

The success of these reforms requires at least two conditions. First, major players in the financial system, particularly banks, should have hard budget constraints and be in a position to exercise self-discipline in their pricing decisions. Second, the demand for credit by borrowers, especially SOEs and financial firms backed by local governments, should be sensitive to changes in interest rates. In particular, implicit government guarantees have to be removed for a sound banking system. Otherwise, banks may expect the government to bail out potential failures when competing for deposits by raising interest rates and/or chasing after returns by lowering lending standards. Establishing an explicit exit mechanism for financial 
institutions is a priority and can contain moral hazard. A depositprotection scheme would be an important element in developing the conditions for fully liberalized deposit rates, as suggested by the experience of many other economies. The PBC is generally expected to launch such a scheme soon.

In short, as a price discovery process, interest rate liberalization demands that banks, firms, and households are responsible for their own decisions and aware of the risks associated with any given return. Before that, the PBC may still need to use measures like aggregate loan quotas even after liberalized deposit rates have moved close to the equilibrium levels.

\section{Concluding Remarks}

In this paper, we have discussed interest rate determination in China before and after interest rate liberalization. There are many questions that we have not addressed. For example, we have argued that short-term interest rates in the bond markets may increase after liberalization on the basis of our empirical findings, but we have not examined the potential effects on the curvature of the yield curve. The liquidity preference and risk appetite of market participants may shift, following interest rate reforms. Regulatory and market structures may also change and shape pricing behaviors. Moreover, we have focused on a closed-economy setting throughout this paper. As a continental-sized economy and with more flexible exchange rates, China is expected to be able to conduct fairly independent monetary policy and anchor the short-term interest rates well. However, since the authorities have also announced plans to accelerate the pace of capital account liberalization, the size, direction, and volatility of gross and net capital flows would inevitably affect the interest rate structure in China. These issues are left for future research. 


\section{Appendix. Equilibrium Interest Rate in the Ramsey Model}

Consider a standard neoclassical model like that of Ramsey (1928). The representative agent has an instantaneous utility function of the constant-relative-risk-aversion form:

$$
u(C(t))=\frac{C(t)^{1-\frac{1}{\sigma}}}{1-\frac{1}{\sigma}},
$$

where $C(t)$ denotes consumption and $\sigma$ governs the elasticity of substitution between consumption at any two points in time. Let $L$ denote labor supplied by the agent and $A$ denote the effectiveness of labor. Assume that the rate of technological progress is $g$, i.e., $A=g A$. The law of motion of the ratio of the agent's asset to effective labor, $x=X / A L$, is then obtained as

$$
\dot{x}(t)=(r(t)-g) x(t)+w(t)-c(t) .
$$

Taking interest rate $r(t)$ and wage rate $w(t)$ as given, the agent chooses paths of consumption $c(t)=C(t) / A L$ and asset $x(t)$ to maximize utility at time $t=0$ :

$$
B \int_{0}^{\infty} \exp (-\beta t) \frac{c(t)^{1-\frac{1}{\sigma}}}{1-\frac{1}{\sigma}} d t
$$

where $B \equiv A(0)^{1-\frac{1}{\sigma}} L(0)$ and $\beta \equiv \rho-\left(1-\frac{1}{\sigma}\right) g>0$, with $\rho$ being the rate of time preference. Subject to the law of motion of $x(t)$ and the no-Ponzi-game condition, maximization yields

$$
\frac{\dot{c}(t)}{c(t)}=\sigma\left[r(t)-\rho-\frac{1}{\sigma} g\right] .
$$

Meanwhile, firms employ the stocks of labor and capital, pay them their marginal products, and sell the resulting output. And all markets clear.

On the balanced growth path, we must have $\dot{c}(t)=0$, which implies

$$
r^{*}=\rho+\frac{1}{\sigma} g .
$$


Since output grows at constant rate $g$ on the balanced path, this gives equation (1).

\section{References}

Bai, C.-E., C.-T. Hsieh, and Y. Qian. 2006. "The Return to Capital in China." Brookings Papers on Economic Activity 37 (2): 61-102.

Caselli, F., and J. Feyrer. 2007. "The Marginal Product of Capital." Quarterly Journal of Economics 122 (2): 535-68.

Chow, G. 1993. "Capital Formation and Economic Growth in China." Quarterly Journal of Economics 108 (3): 809-42.

Funke, M., and M. Paetz. 2013. "Financial System Reforms and China's Monetary Policy Framework." Presented at the Fourth HKIMR Annual International Conference on the Chinese Economy, Hong Kong, January 10-11.

Gali, J. 2003. "New Perspectives on Monetary Policy, Inflation, and the Business Cycle." In Advances in Economics and Econometrics, Vol. 3, ed. M. Dewatripont, L. Hansen, and S. Turnovsky. Cambridge, UK: Cambridge University Press.

Garnier, J., and B.-R. Wilhelmsen. 2005. "The Natural Real Interest Rate and the Output Gap in the Euro Area: A Joint Estimation." ECB Working Paper No. 546.

He, D., and H. Wang. 2012. "Dual-Track Interest Rates and the Conduct of Monetary Policy in China." China Economic Review 23 (4): 928-47.

- 2013. "Monetary Policy and Bank Lending - Evidence from Loan-Level Data." Working Paper No. 16, Hong Kong Institute for Monetary Research.

International Monetary Fund. 2008. "A New Database of Financial Reforms." IMF Working Paper No. 08/266.

Jiang, X. 2012. "The Funds Transfer Pricing System of Commercial Banks in China." Journal of Finance and Economics (in Chinese) 8: 59-61.

Lardy, N. 2008. "Financial Repression in China." Working Paper No. PB08-8, Peterson Institute for International Economics.

Laubach, T., and J. C. Williams. 2003. "Measuring the Natural Rate of Interest." Review of Economics and Statistics 85 (4): 1063-70. 
Manrique, M., and J. M. Marqués. 2004. "An Empirical Approximation of the Natural Rate of Interest and Potential Growth." Working Paper No. 0416, Banco de España.

Mesonnier, J.-S., and J.-P. Renne. 2007. "A Time-Varying 'Natural' Rate of Interest for the Euro Area." European Economic Review 51 (7): 1768-84.

Qin, D., Z. Xu, and X. Zhang. 2013. "How Much Has Private Credit Lending Reacted to Monetary Policy in China? The Case of Wenzhou." Working Paper No. 178, Department of Economics, The School of Oriental and African Studies.

Ramsey, F. P. 1928. "A Mathematical Theory of Saving." Economic Journal 38 (152): 543-59.

Song, Z., K. Storesletten, and F. Zilibotti. 2011. "Growing Like China." American Economic Review 101 (1): 196-233.

Taylor, J. B. 1993. "Discretion versus Policy Rules in Practice." Carnegie-Rochester Conference Series on Public Policy 39: 195214.

World Bank. 2011. The Changing Wealth of Nations. Washington, DC: The World Bank.

Yi, G. 2009. "Progress of Interest Rate Liberalization in China during the 30 Years of Reform." Journal of Financial Research (in Chinese) 343 (1): 1-14.

Zhang, X. 2012. China Monetary Policy. Beijing, China: China Financial Publishing Housing.

Zhou, X. 2010. "Some Thoughts about Advancing Interest Rate Liberalization in China." Available at http://www.pbc.gov.cn/ publish/goutongjiaoliu/524/2012/20120112160648353655534/ 20120112160648353655534_.html (in Chinese).

2013. "Deepen All-Round Financial Reforms and Openness, Quicken the Development of a Financial Market System." Available at http://www.pbc.gov.cn/publish/goutongjiaoliu/ 524/index.html (in Chinese). 